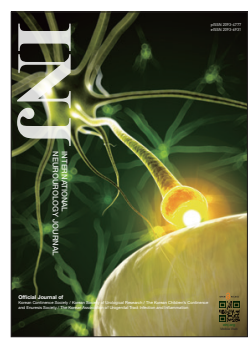

\title{
Urodynamic Mechanisms Underlying Overactive Bladder Symptoms in Patients With Parkinson Disease
}

\author{
Gregory Vurture', Benoit Peyronnet ${ }^{1,2}$, Jose-Alberto Palma ${ }^{3}$, Rachael D. Sussman ${ }^{1}$, Dominique R. Malacarne ${ }^{1}$, Andrew Feigin ${ }^{4}$, \\ Ricardo Palmerola ${ }^{1}$, Nirit Rosenblum ${ }^{1}$, Steven Frucht ${ }^{4}$, Horacio Kaufmann ${ }^{3}$, Victor W. Nitti ${ }^{1}$, Benjamin M. Brucker ${ }^{1}$ \\ ${ }^{1}$ Department of Urology, New York University School of Medicine, New York, NY, USA \\ ${ }^{2}$ Department of Urology, University of Rennes, Rennes, France \\ ${ }^{3}$ Department of Neurology Dysautonomia Center, New York University School of Medicine, New York, NY, USA \\ ${ }^{4}$ The Marlene \& Paolo Fresco Institute for Parkinson's \& Movement Disorders, New York University School of Medicine, New York, NY, USA
}

\begin{abstract}
Purpose: To assess the urodynamic findings in patients with Parkinson disease (PD) with overactive bladder symptoms. Methods: We performed a retrospective chart review of all $\mathrm{PD}$ patients who were seen in an outpatient clinic for lower urinary tract symptoms (LUTS) between 2010 and 2017 in a single-institution. Only patients who complained of overactive bladder $(\mathrm{OAB})$ symptoms and underwent a video-urodynamic study for these symptoms were included. We excluded patients with neurological disorders other than PD and patients with voiding LUTS but without OAB symptoms.

Results: We included 42 patients ( 29 men, 13 women, $74.5 \pm 8.1$ years old). Seven patients (16.7\%) had a postvoid residual (PVR) bladder volume $>100 \mathrm{~mL}$ and only one reported incomplete bladder emptying. Detrusor overactivity (DO) was found in all 42 patients (100\%) and was terminal in $19(45.2 \%)$ and phasic in 22 patients (52.4\%). Eighteen patients had detrusor underactivity (DU) (42.3\%). Later age of PD diagnosis was the only parameter associated with $\mathrm{DU}(\mathrm{P}=0.02)$. Patients with bladder outlet obstruction $(\mathrm{BOO})$ were younger than patients without $\mathrm{BOO}$ (70.1 years vs. 76.5 years, $\mathrm{P}=0.004)$, had later first sensation of bladder filling $(173.5 \mathrm{~mL}$ vs. $120.3 \mathrm{~mL}, \mathrm{P}=0.02)$ and first involuntary detrusor contraction $(226.4 \mathrm{~mL}$ vs. 130.4 $\mathrm{mL}, \mathrm{P}=0.009$ ).

Conclusions: $\mathrm{DO}$ is almost universal in all patients with PD complaining of OAB symptoms (97.1\%). However, a significant percentage of patients also had BOO (36.8\%), DU (47\%), and increased PVR (16.7\%) indicating that neurogenic DO may not be the only cause of $\mathrm{OAB}$ symptoms in $\mathrm{PD}$ patients.
\end{abstract}

Keywords: Detrusor overactivity; Parkinsonism; Urinary bladder; Urinary incontinence; Urodynamics

- Research Ethics: This study was approved by the Institutional Review Board (IRB) of New York University Langone Health (approval number: i17-01776). IRB did not require the written informed consent due to a retrospective nature of our study.

- Conflict of Interest: No potential conflict of interest relevant to this article was reported.

\section{INTRODUCTION}

Parkinson disease (PD) is a neurodegenerative disorder caused by the abnormal deposition of the protein alpha-synuclein in the central and peripheral nervous systems. PD is one of the most frequent neurodegenerative disorders, with a prevalence of 100 to 180 per 100,000 people [1]. In addition to the wellknown motor deficits of the disease (tremors, rigidity, and bradykinesia), patients with PD frequently have nonmotor symptoms including dysphagia, constipation, orthostatic hypoten-

Corresponding author: Benjamin M. Brucker (iD https://orcid.org/0000-0003-1699-3871 Department of Urology, New York University, 222 East 41st Street, New York, NY 10017, USA

E-mail: Benjamin.brucker@nyulangone.org / Tel: +1-6468256327

Submitted: May 4, 2019 / Accepted after revision: June 27, 2019 
sion, depression, cognitive decline, dementia, sexual dysfunction, and lower urinary tract symptoms (LUTS) [2].

Overactive bladder $(\mathrm{OAB})$ symptoms including urinary urgency, frequency, and nocturia, occurring or without urgency incontinence are the most common LUTS in patients with PD [3]. Urinary dysfunction in patients with PD is classically attributed to impaired neural control of the micturition reflex, due to disease-specific suprapontine damages (altered signaling in the nigrostriatal dopaminergic system postulated to affect the inhibitory input to the pontine micturition center through the periaqueductal grey) or alpha-synuclein-related dysfunction of the lower urinary tract autonomic nervous system [4]; however, comorbidities frequent in the elderly population such as benign prostatic hyperplasia $(\mathrm{BPH})$ or pelvic organ prolapse $(\mathrm{POP})$, can contribute to $\mathrm{OAB}$ symptoms in patients with $\mathrm{PD}$ [4].

The role of urodynamics in patients with $\mathrm{PD}$ and $\mathrm{OAB}$ symptoms remains unexplored. Several studies have described urodynamic findings in patients with $\mathrm{PD}$ patients with nonspecific LUTS (i.e., storage and/or voiding symptoms) but no studies have specifically described these findings in patients with $\mathrm{PD}$ and $\mathrm{OAB}$ symptoms [4]. We hypothesized that urodynamic testing could be useful to delineate the underlying pathophysiology of $\mathrm{OAB}$ symptoms in patients with PD.

\section{MATERIALS AND METHODS}

\section{Study Design}

We performed a retrospective chart review of patients diagnosed with PD who were seen in an outpatient clinic with a main complain of symptoms of OAB between 2010 and 2017 in a single-institution. This study was approved by the Institutional Review Board of New York University Langone Health (approval number: i17-01776). We searched specific International Classification of Diseases (ICD) codes in the electronic medical record (ICD9: 320, 332; ICD10: G20, G21). Only patients who complained of $\mathrm{OAB}$ symptoms and underwent a video-urodynamic study (VUD) in the assessment of these symptoms were included. Patients with PD with OAB symptoms were defined as those experiencing urinary urgency, frequency, and/or nocturia, with or without urgency incontinence. Exclusion criteria were: patients with neurological disorders other than PD such as secondary or atypical parkinsonism, and patients with $\mathrm{PD}$ without an evaluation by a movement disorders specialist.

\section{PD Assessment}

After careful history taking, diligent physical exam with use of the Unified Parkinson Disease Rating Scale (UPDRS) to gauge severity of PD [5], the movement disorder specialist determined if the patient met the clinical evidence to warrant a diagnosis of PD. The following rating scales were obtained: the UPDRS, the modified Hoehn and Yahr (H\&Y) stages, and, Schwab and England activities of daily living (S\&E ADL) scale [5]. The Levodopa equivalent daily dose (LEDD) [6] was calculated for each patient using dopaminergic medication dosages at the time of VUD.

\section{Video-Urodynamic Studies}

All video-urodynamics were performed with 7F transurethral and rectal balloon catheters according to the International Continence Society standards [7]. Patients were standardly asked to empty their bladder before the study and the first step was to measure the postvoid residual (PVR) volume taken from the $7 \mathrm{~F}$ urethral catheter placed. Filling cystometry was then performed at a rate of $50 \mathrm{~mL} / \mathrm{min}$ with radiographic contrast material, or at a decreased rate of $30 \mathrm{~mL} / \mathrm{min}$ in cases of severe detrusor overactivity (DO) or known small functional capacity, which was done in most of the patients included in the present series. A pressure-flow study was then performed and fluoroscopic images were obtained at selected times as determined by the clinical scenario (i.e., filling, Valsalva, void/attempt to void, after voiding). The PVR was reassessed after the pressure-flow study. A blind review of all the urodynamic traces was done by a urodynamic expert. The following urodynamics data, defined according to the International Continence Society guidelines [7], were collected: cystometric capacity $(\mathrm{mL})$, volume at first sensation of bladder filling $(\mathrm{mL})$, volume at first uninhibited detrusor contraction $(\mathrm{mL})$, the pattern of DO (phasic vs. terminal), maximum flow rate $(\mathrm{Qmax}, \mathrm{mL} / \mathrm{sec})$, detrusor pressure at maximum flow (PdetQmax, $\mathrm{cm} \mathrm{H}_{2} \mathrm{O}$ ).

Bladder outlet obstruction (BOO) was evaluated from the urodynamic traces by calculating the $\mathrm{BOO}$ index (BOOI) in male patients with $\mathrm{BOOI}>40$ defining $\mathrm{BOO}[8]$ and using the "1998 cut points" (Qmax $<15 \mathrm{~mL} / \mathrm{sec}$ and PdetQmax $>20 \mathrm{~cm}$ $\mathrm{H}_{2} \mathrm{O}$ on pressure-flow study defining BOO) in female patients [9]. BOO was also assessed using a previously described VUD criteria: radiographic evidence of obstruction between the bladder neck and distal urethra in the presence of a sustained detrusor contraction fluoroscopic imaging of the bladder outlet during voiding [10]. Patients were considered obstructed if they 
fulfilled one of the BOO criterion (either the pressure-flow or the video-urodynamic definitions) or both. As recently described, detrusor underactivity (DU) was defined as a combination of Bladder Contractility Index $(\mathrm{BCI})<100$ and BOOI $<20$ in male patients and as a combination of PdetQmax $<20$ $\mathrm{cm} \mathrm{H}_{2} \mathrm{O}$ and Qmax $<15 \mathrm{~mL} / \mathrm{sec}$ in female patients, excluding those with clinically observed obstruction [11].

\section{Statistical Analysis}

Means and standard deviations were reported for continuous variables and proportions for nominal variables. Univariate analyzes using the Fisher exact test or the chi-square test for nominal variables, and the Mann-Whitney test for continuous variables were performed to seek for clinical predictive factors of various urodynamic parameters and to compare urodynamic features of male and female patients. Statistical analyses were performed using JMP v.10.0 software (SAS Institute Inc., Cary, NC, USA). All tests were 2-sided with a significance level at $\mathrm{P}<0.05$.

\section{RESULTS}

\section{Patients' Characteristics}

Forty-two patients with PD and OAB symptoms who had a VUD were included (Fig. 1). Patients' characteristics are summarized in Table 1. The average age at the time of VUD was 74.5 years, 29 of the patients were men $(69 \%$ vs. $31 \%)$ and the average body mass index was $25.9 \mathrm{~kg} / \mathrm{m}^{2}$. The mean disease $\mathrm{du}-$ ration of PD at the time of VUD was 6.6 years. All patients had urgency, 37 had urgency incontinence (88.1\%), and 31 had nocturia (73.8\%) with 3 episodes per night on average.

On neurological examination, the patients had an average

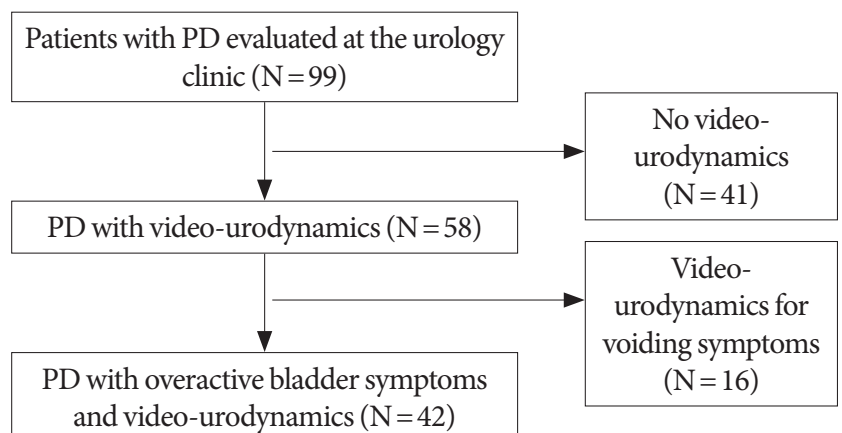

Fig. 1. Patient flow chart: video-urodynamic study and overactive bladder in Parkinson disease (PD).
UPDRS score of 59.5, a median H\&Y stage of 2.5, and S\&E ADL of $69.3 \%$ independence. At the time of VUD, patients were receiving a LEDD of $513.1 \mathrm{mg}$.

Prior to VUD, urological medications included anticholinergics in 31 of the 42 patients (70.5\%), mirabegron in 25 patients (56.8\%), and alpha-adrenergic blockers in 14 patients (31.8\%).

Table 1. Characteristics of patients with Parkinson disease $(\mathrm{n}=42)$

\begin{tabular}{lc}
\hline Characteristic & Value \\
\hline Age (yr) & $74.5 \pm 8.1$ \\
Sex & \\
Men & $29(69.0)$ \\
Women & $13(31.0)$ \\
Disease duration (yr) & $6.6 \pm 5.4$ \\
UPDRS (/199) & $59.5 \pm 19.9$ \\
Hoehn and Yahr staging (/5), median (IQR) & $2.5(2-3)$ \\
Schwab \& England ADL (\%) & $69.3 \pm 22.2$ \\
Levodopa equivalent daily dose (mg) & $513.1 \pm 458.4$ \\
Body mass index (kg/m ${ }^{2}$ ) & $25.9 \pm 5.0$ \\
Previous treatment of LUTS/OAB & \\
Anticholinergics & $31(70.5)$ \\
Mirabegron & $25(56.8)$ \\
Alpha-adrenergic blockers & $14(31.8)$ \\
BPH Surgery (TURP or Greenlight) & $9(20.5)$ \\
Intradetrusor botulinum toxin & $2(4.5)$ \\
No prior treatment & $3(7.1)$ \\
\hline
\end{tabular}

Values are presented as mean \pm standard deviation or number (\%) unless otherwise indicated.

UPDRS, Unified Parkinson Disease Rating Scale; IQR, interquartile range; ADL, activities of daily living; LUTS, lower urinary tract symptoms; $\mathrm{OAB}$, overactive bladder; $\mathrm{BPH}$, benign prostatic hypertrophy; TURP, transurethral resection of prostate.

Table 2. Patients' urodynamic findings $(\mathrm{n}=42)$

\begin{tabular}{lc}
\hline Variable & Value \\
\hline PVR $(\mathrm{mL})$ & $57.3 \pm 101.1$ \\
Maximum flow rate $(\mathrm{mL} / \mathrm{sec})$ & $10.2 \pm 6.1$ \\
First sensation of bladder filling $(\mathrm{mL})$ & $139.5 \pm 122.6$ \\
Involuntary detrusor contraction & $41(97.6)$ \\
Yes & $1(2.4)$ \\
No & $168.2 \pm 140.0$ \\
Volume of 1st uninhibited contraction $(\mathrm{mL})$ & $274.8 \pm 174.3$ \\
Maximum cystometric capacity $(\mathrm{mL})$ & $36.2 \pm 19.5$ \\
Detrusor pressure at maximum flow $\left(\mathrm{cm} \mathrm{H}_{2} \mathrm{O}\right)$ &
\end{tabular}

Values are presented as mean \pm standard deviation or number (\%). PVR, postvoid residual. 
Additionally, 9 patients had a history of transurethral resection of prostate (TURP) or Greenlight (20.5\%) and 2 patients had intradetrusor botulinum toxin injections (4.5\%). Three patients (7.1\%) had never undergone treatment for OAB symptoms prior to the study.

\section{Urodynamic Findings in the Whole Cohort}

The urodynamic findings are summarized in Table 2 . The filling rate was $30 \mathrm{~mL} / \mathrm{min}$ in $32(76.2 \%)$ and $50 \mathrm{~mL} / \mathrm{min}$ in $10 \mathrm{pa}-$ tients (23.8\%). Immediately before the VUD study, patients had an average PVR of $57.3 \mathrm{~mL}$. Seven of the 42 patients (16.7\%) had a PVR $>100 \mathrm{~mL}$ and only 1 of these patients reported a sensation of incomplete bladder emptying on clinical interview. DO was detected in 41 of 42 patients (97.1\%). The mean volume of the 1st uninhibited detrusor contraction was $168.2 \mathrm{~mL}$, and DO was terminal in 19 (46.3\%) and phasic in 22 patients (53.7\%) respectively. The first sensation of bladder filling occurred on average at $139.5 \mathrm{~mL}$ with an average cystometric capacity of $274.8 \mathrm{~mL}$.

\section{Detrusor Underactivity}

Four patients were unable to void during the VUD, although they were voiding clinically, which impeded the performance a pressure-flow study and to assess properly BOO and detrusor contractility in this subgroup. According to the aforementioned sex-specific criteria, 18 patients had DU (47.4\%). Urodynamic and demographic features of those with DU and normal detrusor activity are summarized in Table 3. DU was equally distributed between men $(46.6 \%)$ and women $(50 \% ; \mathrm{P}=0.82)$. The mean BCI was 92.4 in male patients and the mean PdetQmax in female patients was $22.6 \mathrm{~cm} \mathrm{H}_{2} \mathrm{O}$. Patients with DU tended to be older than patients with normal detrusor contractility ( 76.2 years vs. 72.3 years, $\mathrm{P}=0.12$ ) and were diagnosed older with $\mathrm{PD}$ (age of onset 69.1 years vs. 63.6 years, $\mathrm{P}=0.02$ ) but with similar duration of disease (6.1 years vs. 6.6 years, $\mathrm{P}=0.92$ ). There was a trend towards earlier involuntary detrusor contraction (IDC) during filling cystometry in patients with DU $(133.6 \mathrm{~mL}$ vs. $198.4 \mathrm{~mL}$, $\mathrm{P}=0.06)$. Other demographics and urodynamic features did not differ significantly between patients with and without DU, with notably similar PVR (49.8 mL vs. $70.2 \mathrm{~mL}, \mathrm{P}=0.70)$ but also comparable PD characteristics (LEDD, $\mathrm{P}=0.74$; UPDRS, $\mathrm{P}=$ 0.87 ; $\mathrm{H} \& \mathrm{Y}$ stage, $\mathrm{P}=0.54$; and $\mathrm{S} \& \mathrm{E} \mathrm{ADL}, \mathrm{P}=0.09$ ).

\section{Bladder Outlet Obstruction}

When analyzing the fluoroscopic imaging of each patient, $\mathrm{BOO}$ was identified in 9 patients (23.7\%), while based on pressureflow traces, 8 were obstructed (21.1\%). Overall 14 patients fulfilled at least 1 of the 2 urodynamic criteria for BOO (36.8\%). The demographics and urodynamic features of obstructed vs. unobstructed patients are presented in Table 4. BOO was equally distributed between male (38.5\%) and female patients (33.3\%, $\mathrm{P}=0.76)$. From the 4 female patients diagnosed with

Table 3. Demographics and urodynamic features in patients with detrusor underactivity vs. normal detrusor contractility

\begin{tabular}{lcc}
\hline Variable & $\begin{array}{c}\text { Detrusor underactivity }{ }^{\mathrm{a}} \\
(\mathrm{n}=18)\end{array}$ & $\begin{array}{c}\text { Detrusor with normal contractility } \\
(\mathrm{n}=20)\end{array}$ \\
\hline PVR $(\mathrm{mL})$ & $49.8 \pm 108.1$ & $70.2 \pm 104.1$ \\
First sensation of bladder filling $(\mathrm{mL})$ & $134.9 \pm 133.5$ & $146.6 \pm 121.4$ \\
First uninhibited detrusor contraction $(\mathrm{mL})$ & $133.6 \pm 128.3$ & $198.4 \pm 149.5$ \\
Detrusor overactivity & $17(94.4)$ & $20(100)$ \\
Phasic & $6(35.3)$ & $9(45)$ \\
Terminal & $11(58.8)$ & $11(55)$ \\
Sex & & 0.55 \\
Male & $12(66.7)$ & $14(70)$ \\
Female & $6(33.3)$ & $6(30)$ \\
Age (yr) & $76.2 \pm 4.9$ & $72.3 \pm 8.1$ \\
Mean age of PD diagnosis (yr) & $69.1 \pm 7.8$ & 6.82 \\
\hline
\end{tabular}

Values are presented as mean \pm standard deviation or number (\%).

PVR, postvoid residual; PD, Parkinson disease.

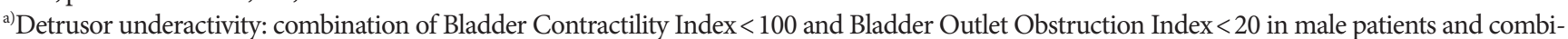
nation of detrusor pressure at max flow $<20 \mathrm{~cm} \mathrm{H}_{2} \mathrm{O}$ and maximum flow rate $<15 \mathrm{~mL} / \mathrm{sec}$ in female patients, excluding those with clinically observed obstruction. 
Table 4. Demographics and urodynamic features in patients with bladder outlet obstruction vs. no bladder outlet obstruction

\begin{tabular}{|c|c|c|c|}
\hline Variable & $\begin{array}{l}\text { Bladder outlet obstruction }^{\mathrm{a})} \\
\qquad(\mathrm{n}=14)\end{array}$ & $\begin{array}{l}\text { No bladder outlet obstruction } \\
\qquad(\mathrm{n}=24)\end{array}$ & P-value \\
\hline PVR (mL) & $86.6 \pm 116.6$ & $45.2 \pm 97$ & 0.38 \\
\hline First sensation of bladder filling (mL) & $173.5 \pm 132.9$ & $120.3 \pm 117.8$ & 0.02 \\
\hline First uninhibited detrusor contraction (mL) & $226.4 \pm 150.3$ & $130.4 \pm 125.3$ & 0.009 \\
\hline $\begin{array}{l}\text { Detrusor overactivity } \\
\text { Phasic } \\
\text { Terminal }\end{array}$ & $\begin{array}{r}14(100) \\
8(57.1) \\
6(42.9)\end{array}$ & $\begin{array}{l}23(95.8) \\
10(41.7) \\
14(58.3)\end{array}$ & 0.36 \\
\hline $\begin{array}{l}\text { Sex } \\
\text { Male } \\
\text { Female }\end{array}$ & $\begin{array}{r}10(71.4) \\
4(28.6)\end{array}$ & $\begin{array}{r}15(62.5) \\
9(37.5)\end{array}$ & 0.82 \\
\hline Age (yr) & $70.1 \pm 5.7$ & $76.5 \pm 6.6$ & 0.004 \\
\hline Age of PD diagnosis (yr) & $64.1 \pm 7.6$ & $67.4 \pm 8.2$ & 0.2 \\
\hline
\end{tabular}

Values are presented as mean \pm standard deviation or number $(\%)$.

PVR, postvoid residual; PD, Parkinson disease.

${ }^{\text {a) }}$ Bladder outlet obstruction: bladder outlet obstruction index (BOOI) $>40$ in male patients and maximum flow rate $<15 \mathrm{~mL} / \mathrm{sec}$ and detrusor pressure at max flow $>20 \mathrm{~cm} \mathrm{H}_{2} \mathrm{O}$ on pressure-flow study in female patients.

BOO, 3 had undergone previous urethral surgery (midurethral slings in 2, urethroplasty for urethral stricture in one) suggesting anatomical rather than functional obstruction. The mean BOOI was 20.8 in male patients. Patients with BOO were significantly younger than patients without $\mathrm{BOO}$ (70.1 years vs. 76.5 years, $\mathrm{P}=0.004)$ and had later first sensation of bladder filling (173.5 mL vs. $120.3 \mathrm{~mL}, \mathrm{P}=0.02)$ and first IDC (226.4 $\mathrm{mL}$ vs. $130.4 \mathrm{~mL}, \mathrm{P}=0.009$ ).

Other demographics and urodynamic features did not differ significantly between patients with and without $\mathrm{BOO}$, with notably similar PVR ( $86.6 \mathrm{~mL}$ vs. $45.2 \mathrm{~mL}, \mathrm{P}=0.38$ ) but also comparable PD characteristics (LEDD, $\mathrm{P}=0.48$; UPDRS, $\mathrm{P}=0.99$; $\mathrm{H} \& \mathrm{Y}$ stage, $\mathrm{P}=0.69$; and S\&E ADL: $\mathrm{P}=0.44$ ).

\section{DISCUSSION}

Our study strongly suggests that a vast majority of OAB symptoms in patients with PD can be attributed to DO on urodynamics (97.1\%). However, the high rates of other abnormalities such as BOO (36.8\%), DU (47\%), and increased PVR (16.7\%) suggest that neurogenic $\mathrm{DO}$ is not the only contributor of $\mathrm{OAB}$ symptoms in patients with PD.

While the role of urodynamics in the evaluation of patients with idiopathic $\mathrm{OAB}$ is controversial [12], with a growing body of evidence suggesting a poor predictive value of $\mathrm{DO}$ on $\mathrm{OAB}$ treatment outcomes [13], urodynamics could remain an important tool in patients with $\mathrm{PD}$ and $\mathrm{OAB}$ symptoms. $\mathrm{OAB}$ symptoms in patients with $\mathrm{PD}$ are often empirically treated following the idiopathic OAB guidelines. However, the pathophysiology of neurogenic bladder dysfunction in $\mathrm{PD}$ is different from that of nonneurogenic bladder dysfunction affecting the general population. Therefore, urodynamic testing could be a useful tool to comprehensively define the potentially multifactorial pathophysiology of lower urinary tract dysfunction, which may impact treatment decision-making [4].

However, despite $\mathrm{OAB}$ symptoms being the most common urinary clinical feature affecting $27 \%-64 \%$ of patients with $\mathrm{PD}$ $[4,14]$, there is scarce knowledge in the current literature of the urodynamic profile of a patient with PD and storage LUTS. Previous VUD series have only described urodynamic findings of PD patients with any LUTS (i.e., storage and/or voiding symptoms), but none have specifically investigated OAB symptoms in this population $[4,15,16]$. In addition, the 2 largest series to date, performed in 1995 and 2000 respectively, were conducted before the current ICS urodynamic standards were established $[15,16]$.

Previous studies have identified DO as a prevalent urodynamic finding in patients PD and LUTS [3,4,14-16]. DO in patients with PD is classically attributed to impaired neural control of the micturition reflex [3,4,14-16], either through dysregulation of the suprapontine dopaminergic pathway as suggested by the specific features observed on functional brain imaging in PD patients with DO [17], or through alpha-synuclein-related dysfunction of the lower urinary tract autonomic nervous system [18]. 
Several of our findings suggest that DO in our PD cohort may not exclusively result from neurogenic mechanisms. First, we observed a very high rate of BOO (up to $36.8 \%$ ). The relationship between $\mathrm{BOO}$ and $\mathrm{DO}$ has been well established for over 2 decades, $\mathrm{BOO}$ causing specific histological changes in the bladder wall (e.g., patchy denervation, collagen, and elastin infiltration) which mediate electrical coupling between detrusor smooth muscle cells and promote spontaneous myogenic contractions [19]. In view of our findings, it is likely that BOO might contribute to DO in at least some patients with $\mathrm{PD}$ and $\mathrm{OAB}$ symptoms. Finally, as previously evidenced in other series, we found no association between PD severity and urodynamic features supporting the idea that lower urinary tract dysfunction in these patients is not driven exclusively by neurogenic mechanisms $[4,16]$. The etiology of these urodynamic findings is likely multifactorial. It is possible that neurogenic dysfunction in the setting of further obstruction via $\mathrm{BPH}$ could further contribute to DO in this cohort.

In the present series, nearly half of the patients had DU [11], a characteristic finding of multiple system atrophy (MSA), a rare aggressive atypical parkinsonian syndrome [20-22]. However, the same studies also demonstrated impaired detrusor contractility in roughly $40 \%-60 \%$ of patients with PD [21,22]. By showing that detrusor under- and overactivity commonly coexist in patients with PD and OAB symptoms, out study suggest that isolated underactive detrusor with no coexisting overactivity, could assist in distinguishing MSA from PD, as 100\% of patients with $\mathrm{PD}$ and DU had coexisting DO in our cohort.

Another important insight from this high prevalence of DU is that it could worsen $\mathrm{OAB}$ symptoms as of DU symptoms can overlap with those of OAB. For instance, urgency has been reported in $50 \%$ of patients with urodynamic-proven DU [23].

While the relationship between neurological dysfunction and lower urinary dysfunction is straightforward in disorders typically occurring in young patients (e.g., spinal cord injury, spina bifida, and multiple sclerosis) PD, which typically affects elderly patients, can be associated with age-related lower urinary tract conditions, such as $\mathrm{BPH}, \mathrm{POP}$, or stress urinary incontinence but also with ageing-related pathophysiological contributors that aggravate $\mathrm{OAB}$ symptoms (e.g., chronic pelvic ischemia, sex hormone deficiency) [4]. Hence, the pathophysiology of $\mathrm{OAB}$ in patients with $\mathrm{PD}$ is likely to be multifactorial than in other neurological conditions. The slowly progressive nature of PD-related lower urinary tract dysfunctions, which parallels those of the aforementioned lower urinary tract condi- tions and pathophysiological cofactors make the distinction of the contributing factors involved very challenging. In that regard, urodynamics, which could provide the most accurate assessment of the underlying cofactors, might be regarded as a mainstay in the diagnostic workup of these patients. Indeed, several clues in the literature suggest that identifying the underlying mechanisms might help with better tailoring treatment in PD patients with $\mathrm{OAB}$ symptoms. Recent data suggest that TURP might be a valuable option in PD patients with storage LUTS as long as BOO has been properly evidenced through pressure-flow study [24]. In the largest series to date evaluating intradetrusor botulinum toxin injections in PD patients, Vurture et al. [25] found that higher BOO Index was significantly associated with increased failure rate, thus confirming the importance of diagnosing $\mathrm{BOO}$ with urodynamics to improve treatment selection for $\mathrm{PD}$ patients with $\mathrm{OAB}$ symptoms. One could hypothesize that identifying DU could impact treatment decision-making as well. Indeed, recent series suggested that the safety and efficacy of sacral neuromodulation was preserved in patients with DU and coexisting DO while intradetrusor botulinum toxin injections was less effective in this subgroup $[26,27]$. Hypothetically, urodynamic findings might influence the selection of several other treatment options (beta 3 agonist vs. anticholinergics in obstructed vs. unobstructed, etc.). However, further data is needed to strictly determine the predictive value of each of these urodynamic findings on the outcomes of $\mathrm{OAB}$ treatments in the PD population.

Pseudodyssynergia has been described in PD patients as a possible cause of $\mathrm{BOO}$ [28]. Interestingly, while $36.8 \%$ of the patients in our cohort fulfilled at least 1 of the 2 urodynamic criteria for $\mathrm{BOO}$, no case of pseudodyssynergia was diagnosed. The OAB symptoms focus of our study population and relatively low average PVR may explain this finding.

Our study has limitations inherent to its retrospective and nonrandomized design. It was a single-center series from a tertiary referral center, which could have biased our results. Voiding diary at the time of VUD was lacking in many patients. There was no formal standardized assessment to evaluate polyuria and nocturnal polyuria which prevented us from evaluating their contribution to $\mathrm{OAB}$ symptoms pathogenesis and from the possible role of voiding diary data in predicting urodynamic features. The relatively small sample size and inherent lack of statistical power prevented us from assessing more accurately predictive factors of success and complications through multivariate analysis. The lack of validated questionnaires to 
evaluated LUTS is an additional significant drawback. Lack of current consensus on urodynamic definitions of $\mathrm{BOO}$ and $\mathrm{DU}$, especially in women, might have resulted in inaccurate estimations of their prevalence. Finally, the lack of assessment of how urodynamic findings could impact treatment decision-making and outcomes could be regarded as an important shortcoming.

In conclusion, $\mathrm{DO}$ is almost universal in all patients with $\mathrm{PD}$ complaining of OAB symptoms (97.1\%). However, a significant percentage of patients also had BOO (36.8\%), DU (47\%), and increased PVR (16.7\%) indicating that neurogenic DO may not be the only cause of OAB symptoms in PD patients. Further prospective and randomized studies are needed to confirm our findings and to assess how the urodynamic may influence $\mathrm{OAB}$ treatment outcomes in the PD population.

\section{AUTHOR CONTRIBUTION STATEMENT}

- Full access to all the data in the study and takes responsibility for the integrity of the data and the accuracy of the data analysis: $G V, B P$

- Study concept and design: $B P, S F, H K, B B$

- Acquisition of data: $G V, B P, R S, D M, R P, N R$

- Analysis and interpretation of data: $J P, A F, S F, H K, B B$

- Drafting of the manuscript: $G V, B P, J P, A F, S F, H K, V N, B B$

- Critical revision of the manuscript for important intellectual content: $R S, A F, S F, H K, V N, B B$

- Statistical analysis: $G V, B P, R S, D M, R P$

- Administrative, technical, or material support: GV, RS, DM

\section{REFERENCES}

1. National Collaborating Centre for Chronic Conditions. Parkinson's disease: national clinical guideline for diagnosis and management in primary and secondary care. London: Royal College of Physicians; 2006. pp. 121-4.

2. Sakakibara R, Tateno F, Yamamoto T, Uchiyama T, Yamanishi T. Urological dysfunction in synucleinopathies: epidemiology, pathophysiology and management. Clin Auton Res 2018;28:83-101.

3. McDonald C, Winge K, Burn DJ. Lower urinary tract symptoms in Parkinson's disease: prevalence, aetiology and management. Parkinsonism Relat Disord 2017;35:8-16.

4. Brucker BM, Kalra S. Parkinson's disease and its effect on the lower urinary tract: evaluation of complications and treatment strategies. Urol Clin North Am 2017;44:415-28.

5. Movement Disorder Society Task Force on Rating Scales for Par- kinson's Disease. The Unified Parkinson's Disease Rating Scale (UPDRS): status and recommendations. Mov Disord 2003;18:73850.

6. Tomlinson CL, Stowe R, Patel S, Rick C, Gray R, Clarke CE. Systematic review of levodopa dose equivalency reporting in Parkinson's disease. Mov Disord 2010;25:2649-53.

7. Schäfer W, Abrams P, Liao L, Mattiasson A, Pesce F, Spangberg A, et al. Good urodynamic practices: uroflowmetry, filling cystometry, and pressure-flow studies. Neurourol Urodyn 2002;21:261-74.

8. Abrams P. Bladder outlet obstruction index, bladder contractility index and bladder voiding efficiency: three simple indices to define bladder voiding function. BJU Int 1999;84:14-5.

9. Chassagne S, Bernier PA, Haab F, Roehrborn CG, Reisch JS, Zimmern PE. Proposed cutoff values to define bladder outlet obstruction in women. Urology 1998;51:408-11.

10. Nitti VW, Tu LM, Gitlin J. Diagnosing bladder outlet obstruction in women. J Urol 1999;161:1535-40.

11. Gammie A, Kaper M, Steup A, Yoshida S, Dorrepaal C, Kos T, et al. What are the additional signs and symptoms in patients with detrusor underactivity and coexisting detrusor overactivity? Neurourol Urodyn 2018;37:2220-5.

12. Rosier PF, Giarenis I, Valentini FA, Wein A, Cardozo L. Do patients with symptoms and signs of lower urinary tract dysfunction need a urodynamic diagnosis? ICI-RS 2013. Neurourol Urodyn 2014;33: 581-6.

13. Rachaneni S, Latthe P. Effectiveness of BTX-A and neuromodulation in treating $\mathrm{OAB}$ with or without detrusor overactivity: a systematic review. Int Urogynecol J 2017;28:805-16.

14. Ogawa T, Sakakibara R, Kuno S, Ishizuka O, Kitta T, Yoshimura N. Prevalence and treatment of LUTS in patients with Parkinson disease or multiple system atrophy. Nat Rev Urol 2017;14:79-89.

15. Araki I, Kitahara M, Oida T, Kuno S. Voiding dysfunction and Parkinson's disease: urodynamic abnormalities and urinary symptoms. J Urol 2000;164:1640-3.

16. Gray R, Stern G, Malone-Lee J. Lower urinary tract dysfunction in Parkinson's disease: changes relate to age and not disease. Age Ageing 1995;24:499-504.

17. Kitta T, Kakizaki H, Furuno T, Moriya K, Tanaka H, Shiga T, et al. Brain activation during detrusor overactivity in patients with Parkinson's disease: a positron emission tomography study. J Urol 2006;175(3 Pt 1):994-8.

18. Hamill RW, Tompkins JD, Girard BM, Kershen RT, Parsons RL, Vizzard MA. Autonomic dysfunction and plasticity in micturition reflexes in human $\alpha$-synuclein mice. Dev Neurobiol 2012;72:91836. 
19. Andersson KE. Storage and voiding symptoms: pathophysiologic aspects. Urology 2003;62(5 Suppl 2):3-10.

20. Defreitas GA, Lemack GE, Zimmern PE, Dewey RB, Roehrborn CG, O’Suilleabhain PE. Distinguishing neurogenic from non-neurogenic detrusor overactivity: a urodynamic assessment of lower urinary tract symptoms in patients with and without Parkinson's disease. Urology 2003;62:651-5.

21. Sakakibara R, Hattori T, Uchiyama T, Yamanishi T. Videourodynamic and sphincter motor unit potential analyses in Parkinson's disease and multiple system atrophy. J Neurol Neurosurg Psychiatry 2001;71:600-6.

22. Kim M, Jung JH, Park J, Son H, Jeong SJ, Oh SJ, et al. Impaired detrusor contractility is the pathognomonic urodynamic finding of multiple system atrophy compared to idiopathic Parkinson's disease. Parkinsonism Relat Disord 2015;21:205-10.

23. Uren AD, Cotterill N, Harding C, Hillary C, Chapple C, Klaver M, et al. Qualitative exploration of the patient experience of underac- tive bladder. Eur Urol 2017;72:402-7.

24. Roth B, Studer UE, Fowler CJ, Kessler TM. Benign prostatic obstruction and parkinson's disease--should transurethral resection of the prostate be avoided? J Urol 2009;181:2209-13.

25. Vurture G, Peyronnet B, Feigin A, Biagioni MC, Gilbert R, Rosenblum N, et al. Outcomes of intradetrusor onabotulinum toxin A injection in patients with Parkinson's disease. Neurourol Urodyn 2018;37:2669-77.

26. Hennessey DB, Hoag N, Gani J. Sacral neuromodulation for detrusor hyperactivity with impaired contractility. Neurourol Urodyn 2017;36:2117-22.

27. Wang CC, Lee CL, Kuo HC. Efficacy and safety of intravesical OnabotulinumtoxinA injection in patients with detrusor hyperactivity and impaired contractility. Toxins (Basel) 2016 Mar 18;8(3). pii: E82. https://doi.org/10.3390/toxins8030082.

28. Dmochowski RR. Female voiding dysfunction and movement disorders. Int Urogynecol J Pelvic Floor Dysfunct 1999;10:144-51. 